\title{
Non-invasive cardiac output monitoring during sinus surgery
}

\author{
Suneeta Gollapudy $\cdot$ Matthias L. Riess
}

Received: 28 November 2014 / Accepted: 6 December 2014 / Published online: 28 December 2014

(C) Japanese Society of Anesthesiologists (outside the USA) 2014

Keywords Anesthetic · Controlled hypotension · Opioid · Safety $\cdot$ Surgical field

To the Editor:

We read with interest the study "Comparison of the hemodynamic effects of nitroprusside and remifentanil for controlled hypotension during endoscopic sinus surgery" [1]. Endoscopic sinus surgery (ESS) patients were randomized to receive intravenous nitroprusside or remifentanil for controlled hypotension $(\mathrm{CH})$. We commend the authors to use a novel non-invasive cardiac output monitor to assess hemodynamic changes during ESS. As expected, nitroprusside resulted in decreased stroke volume with concomitantly increased heart rate that led to the same cardiac output as with remifentanil. Cardiac output was lower in both groups compared to baseline along with a significant decrease in total peripheral resistance. It remains unclear [2] if $\mathrm{CH}$ results in less local bleeding regardless of how $\mathrm{CH}$ is achieved or if lower cardiac output, e.g., by betablockade, is superior to decreased vascular resistance. Unfortunately, this study is a missed opportunity as it did not investigate if the observed hemodynamic changes in fact lead to a difference in local bleeding and therefore does not provide any new knowledge why vasodilators like nitroprusside seem less efficient than using remifentanil as part of a total intravenous anesthetic technique. Thus, despite its good intentions, this study has limited value to assist the clinician in choosing the best anesthetic technique to make sinus surgery safer.

Respectfully,

S. Gollapudy MD

M. Riess MD PhD

Acknowledgments Funding was provided by VA (CARA-026$10 \mathrm{~F}), \mathrm{NIH}$, and institutional funds.

\section{References}

1. Yun SH, Kim JH, Kim HJ. Comparison of the hemodynamic effects of nitroprusside and remifentanil for controlled hypotension during endoscopic sinus surgery. J Anesth. 2014. doi:10.1007/ s00540-014-1856-0.

2. Kelly EA, Gollapudy S, Riess ML, Woehlck HJ, Loehrl TA, Poetker DM. Quality of surgical field during endoscopic sinus surgery: a systematic literature review of the effect of total intravenous compared to inhalational anesthesia. Int Forum Allergy Rhinol. 2013;3:474-81.

\section{S. Gollapudy}

Department of Anesthesiology, Medical College of Wisconsin,

Milwaukee WI 53226, USA

\section{L. Riess ( $\square)$}

Department of Anesthesiology, TVHS VA Medical Center, 1310

24th Avenue South, Nashville TN 37212, USA

e-mail: matthias.riess@ vanderbilt.edu 